\title{
The Innovation and Practice of Higher Quality Applied Talent Cultivation for Civil Engineering Specialty in Local Universities
}

\author{
Zhong Xingu, Xie Xianzhong, Nie Yihua, He Jianqing \\ School of Civil Engineering, Hunan University of Science and Technology, Xiangtan, China \\ e-mail:464397070@qq.com, 872751321@qq.com, nieyihua@sohu.com,249194156@qq.com
}

Keywords: Civil engineering specialty; Talent cultivation; Innovation; Practice; Effect evaluation

\begin{abstract}
Combined with the project implementation of Talent Cultivation Mode Innovation Zone for Civil Engineering Specialty in Local Universities, the talent cultivation mode for civil engineering specialty with the characteristics of practice, application, entrepreneurship and innovation has been established, and curriculum system with the features of two, two and major professional curriculum has been designed, and the matched two quality control systems for curriculum and practice are put forward together, which are the effective teaching evaluation and feedback system during the whole teaching process, and the specialty comprehensive practice quality and safety monitoring system. The students can obtain the ability of expert in one thing and good at many, and have outstanding engineering practice ability through all-around and multi-channel training under the innovation practice and the whole process quality control for curriculum system and practice project. The effect of this talent cultivation mode is proved to be notable for six years application. The students' abilities of knowledge application and innovation, interpersonal communication and cooperation, social responsibility and working consciousness can be promoted effectively. The relationship between teachers and construction enterprises become more tightly, and the serve range of produce-study-research projects for teachers can be enlarged, and the teaching levels and student's recognition degree for teachers can be improved constantly. A good employment platform can be formed for the students and enterprises to know and understand each other better, which makes the students employment more reasonable, more diverse, and more successful.
\end{abstract}

\section{Introduction}

Eight civil-engineering-related majors have merged into one major civil engineering, according to the undergraduate specialty catalogue in institutions of higher learning issued by the Chinese Ministry of Education in 1998. The construction, management and investment of domestic modern civil engineering are associated with subjects such as ekistics, building, construction, administration and maintenance, which emphasize the features of individuality and integrity. Individuality means that civil engineering is a single project that can't be continuously replicated, tentatively implemented and recalled. Integrity implies that civil engineering projects include argumentation, prospecting, designing, construction, administration and maintenance stages, and investment performance, building law, environment, geology, survey, mechanical calculation, flood hydrology, material, engineering machinery, construction technology, and management must be taken into consideration, involved with academic units, research units, government, etc[1-2]. Construction enterprises develop from single-specialty construction to the mode of build-operate-transfer (BOT). Modern talent cultivation mode has to match the features of modern civil engineering such as multidisciplinary and comprehensiveness. Students graduated from civil engineering in different categories of colleges should have different career expectations[3-6]. 


\section{Orientation of Education Mode}

Currently, institutions of higher education can be classified into two categories, 985, 211 universities (known as the key universities) and local universities which have been following the key universities on education mode and knowledge structure all the time[3]. Enrollment of local universities is by the great civil engineering major as the key universities. Cultivation of multiple-module and flexible teaching are also following the key universities by the principle of the under graduate specialty catalogue of higher institutions carried out in 1998. The difference between key universities and local universities is as follows[3-4].

(1) Due to the academic level of local universities and the disadvantage of district, they are usually inadequate in quality and quantity of teachers.

(2) Lack of education resources results in the failure of cultivation of multiple-module and flexible teaching.

(3) Most of graduates from the local university are going to been employed by construction companies and grassroots units.

In the development of Hunan University of Science and Technology (HUNST), we have realized the disparity between key universities and local universities since 2002. We began to adjust the mode of cultivation based on real conditions. In the process of practicing, we have gradually formed the cultivation mode for civil engineering students, which conformed to our history and character, relying on the setting up of innovation district for civil engineering talents training mode in local universities. The method of cultivation is business-oriented and highlighting practice, application, pioneer and innovation, aiming to train qualified talents for civil engineering enterprises.

\section{Innovation and Practice of Civil Engineering Talents Cultivation Mode}

In the light of the undergraduate specialty catalogue of higher institutions, our school integrates building engineering, geotechnical engineering, municipal engineering, etc. into civil engineering as the enrollment great major.

\section{Specialized and versatile curriculum}

According to the research conducted by key universities, most of which offer civil engineering teaching in class by the large category of subject, multiple-module curriculum is set up and students are allowed to make choices by themselves. Based on our faculty resources, we imitatively start a threemodule curriculum including building engineering, road and bridge engineering and geotechnical engineering, which can be chose by students before the end of sophomore year. We take several different methods to arrange students to these professional directions, such as students with higher examination scores at school or higher scores in the national university entrance examination having the priority to choose their preferred module. But we also encountered some problems such as different social impact, teacher resources and market talent demand expectations of different module's corresponding sub-discipline, which leads to a vast number of students gap between different modules. The module with more students is short of educational resource, while the one with fewer students may cause waste of educational resource. What's more, dividing students into different modules by their ranks could end up in a vicious circle that modules chose by fewer students may get more poor students, which result in harmful academic atmosphere and unhealthy students psychology. However, in the key universities there is small difference in subjects building, teacher resources and social impact of different modules. Furthermore, in the national college entrance examination enrollment, the key universities possess the best group of students. They don't have to worry about problems abovementioned. In consideration of the practice of setting module cultivation and features of modern 
enterprises, we implement enrolling students by modules. We offer relatively definite specialized courses and have respective major courses intersected, to help students make connections and be expert in their module and good at others. This curriculum mode is called " $2+2+$ major courses", which is proved to be suitable for local universities.

\section{Comprehensive capacity development course setting}

Based on high grade students, key universities aim to cultivate innovative elites. However, local universities mostly tend to develop ability to solve practical problems and encourage pioneering spirit. The system of civil engineering courses is set on classical mathematics, taking Newton rigid body mechanics and Lagrange analysis mechanics as main body, combined with professional standard curriculums. Although Newton rigid body mechanics and Lagrange analysis mechanics have not changed for 200 years, the methods and techniques to solve mechanical problems have been changing. With the development of numerical computing technology, personal computer, and user-friendly commercial software, when people deal with complicate structure calculation, what they need is basic concepts of mechanics instead of many techniques, with which they can figure it out by commercial software quickly. Commercial software is highly developed nowadays, so traditional curriculum setting for courses as theoretical mechanics, material mechanics, elastic mechanics and structure mechanics is not applicable any more. By adjusting curriculums, reforming teaching methods, stressing on teaching concepts of mechanics courses, we are trying to help students learn the basic mechanics knowledge and techniques of software for mechanical analysis. Students are supposed to have the ability to judge the input and output of the software. (e.g., students should determine the boundary conditions accurately and indicate the position of bending moment and more stress liberally, and then they should judge the outcome given by software).

Modern construction enterprises no longer run construction only. They operate investment and management at the same time, which demands students know more about investment, business, management and humanism, with the potential to be an entrepreneur. In some sense, to be an entrepreneur, study experience in universities is only one factor. Family background, upbringing and social context are also crucial for one's expectation. The function of universities is providing students with essential knowledge rather than cultivating entrepreneurs or pioneer deliberately.

\section{Comprehensive capacity development practical setting}

Chinese higher education has been changed from elite education to the popular one, and local colleges play a main role in Chinese higher education, with local university students scale constantly expanding and social environment changing. There is a big contrast between the practical aspects of the requirement and conditions of the reality of practice. The practice of civil engineering mainly includes three modules- experiment, practice and graduation or course design. University can make the students finish the experiment in the short term by increasing the equipment properties and reducing the student's number of group. Schools passing through higher school undergraduate teaching evaluation basically can meet the basic requirements of experimental teaching. Traditional curriculum design is to finish some structural design in one to two weeks after the professional standard of the class to realize understanding and application of professional norms course. Students complete their design by their owned personal computer. Also, due to the individually owned computers being widely, there is common students copy phenomenon in the process of graduation design. Curriculum design should be the mode of project based learning, including carefully design ability training, constructing ability question bank, random selection of test questions and examination of students' ability by curriculum design defense. The civil engineering graduation design focuses on cultivating students' ability in three aspects- the comprehensive application of knowledge, initiative learning, and problem solving ability. 
Graduation design process control is more important than ever. All-around process control and diversification subject (e.g., combination with the actual engineering, teachers research topic and employment), achieve the goal to develop the students' abilities.

Traditional professional practice for civil engineering generally included three kinds, so called cognition practice, production practice and graduation practice[7]. By adjusting the curriculum settings, integrating practice categories[8], extending practice time and breaking the boundaries of the semester and holiday, new practice mode is adopted and the enterprises are willing to accept the students. Purpose of student's practice ability training and improving is achieved.

\section{Characteristics Of Civil Engineering Talents Cultivation Mode}

Based on the project Talent Cultivation Mode Innovation Zone for Civil Engineering Specialty in Local Universities, we positioned civil engineering talent cultivation in civil engineering units at the grass-roots. Relying on modern civil engineering characteristics, we highlighted the practice, application, entrepreneurship and innovation characteristics. We cultivate students as applicable talents mastering many skills while specializing in one, the labor management knowledge, with strong practical ability, high entrepreneurship and innovation. After graduation, our students are the potential civil engineers with solid professional basis, professional skilled, fit for the civil engineering construction enterprise. II Platform+Backbone Course Cross Set, Whole Process Mechanics Concept Teaching, and Term and Vacation become the established mode for talent cultivation.

II Platform refers to the public, professional foundation platform(the first two academic years) and professional direction platform(the last two academic years). We enrolled students according to the direction of professional platform, avoiding the negative influence of former direction selection at the third years. Backbone Course Cross Set means one to two main courses from other professional direction are set in one professional direction(e.g., road, bridge professional direction setting building architecture and tunnel engineering courses, construction engineering, geotechnical engineering specialty direction setting bridge project, subgrade engineering courses). These courses are about 60\% of the total courses of the professional direction, mainly for students to learn basic professional knowledge of other professional directions. By the study of platform course for professional direction and cross backbone courses, students are special, pluripotent and comprehensive.

The foundation of civil engineering specialty is mechanics. The traditional mechanics teaching pays attention to the problem solving skills; however the basic concept itself and the evolution are ignored. There is also the problem of the course repetition(e.g., physics and theoretical mechanics include the mechanics of rigid body content, while the mechanics of materials, structural mechanics, structural design also include the same content). If the mechanics teacher is lack of professional background, professional teaching being out of engineering reality is inevitable. To avoid repetition, mechanics curriculum syllabus should be set to the mode of progressive and continuous learning at all the course (e.g., rod, beam and combination of components, material mechanics properties are set to form a whole process mechanics concept teaching mode).

In order to improve the students' engineering practice ability and comprehensive quality, putting teachers as the leading professional comprehensive dispersion internship, students as the main body of process monitoring system production practice and graduation practice are integrated, the curriculum is adjusted and the basic specialized courses are completed in the third academic year. The time of practice is from June of the third academic year to the end of October of the fourth academic year lasting for at least 15 weeks. 


\section{Quality assurance measures and effect analysis of Civil engineering professional personnel training mode}

\section{The organization and leadership}

In order to ensure the project Talent Cultivation Mode Innovation Zone for Civil Engineering Specialty in Local Universities, Hunan University of Science and Technology set up leadership team headed by the school vice principal in charge of teaching, composed of foundation courses related professors, civil engineering professor or experts. By four years practice and research, civil engineering professional personnel training mode has been established, examined and approved by the school. According to the new personnel training mode, as the pilot the road and bridge engineering direction was reformed in grade 2009 and 2010 students, and then the other three directions begin to be reformed. Full implementation of the civil engineering has obtained the remarkable effect.

\section{Assurance measures}

According to the principle high-quality effect by process control, continuous improvement, and comprehensive management work mechanism was set up, students as the main body, teachers as the leading factor, full participation, process control. Control of whole teaching evaluation and feedback system to raise students' ability as the core was set up.

1) A high level of teaching staff: As of March 2015, civil engineering department in Hunan University of Science and Technology have forty seven professional teachers with $75 \%$ teachers under the age of forty including forty one teachers with doctoral degrees. Nearly five years more than 20 items of national natural science fund projects have been undertaken. Lateral research fund entrusted by enterprises is about 110 millions Yuan. Five provincial scientific and technological progress prizes have been won. The bridge and tunnel team of Hunan province science and technology innovation was founded. Over 300 papers and 2 monographs units was published. Young teachers recruited in the past five years all have doctorates, which were cultivated in teaching by appointed old teachers. They participated in technical service training of engineering test center to improve engineering practice ability. By providing mentoring for the young teachers and preferential policies in research project application, all young teachers undertaken national or provincial projects. By independent research of project promoting the academic standards, distinctive young teachers training mode was formed. Teaching and research teams in the analysis of the long-span bridge, bridge and structural wind engineering, structural vibration control, the basic mechanical properties of geotechnical, direction of tunnel engineering and high performance concrete have been formed.

2) Improving operating conditions: In recent years, all kinds of platform funds such as the quality and safety of civil engineering of Hunan province key professional platform construction funds, school selfraised funds have invested more than 4.5 millions, and built the mechanics experiment center, including cement, concrete, asphalt, roadbed, soil mechanics, hydraulics, engineering geology, static structure, dynamic structure(20t vibration table), and wind tunnel laboratories, with laboratory building area of 10000 square meters, providing chance for the undergraduate students to train practice ability. All teachers in the laboratory have civil engineering professional test engineer certificates issued by the government departments and they master skills in relatively different categories of experiment while specializing in one experiment. It is possible for many teachers to guide the same experiment to reduce students' number of experimental group and eliminate the phenomenon of onlookers during experiments.

3)The quality control of the whole teaching evaluation and feedback system: Based on the highquality effect by process control in the civil engineering construction, process control modes in class teaching, practice teaching, and the course design have been formed taking student as the main body, setting up teaching process control and feedback mechanism of students teaching evaluation, teachers 
and students mutually evaluation, experts of the steering team spot check. Class teaching is the main way for students' knowledge acquisition and teachers being all in for class teaching is the important guarantee to realize training mode. Front-term preparation inspection, the mid-term examination and end-term inspection are necessary. New course, new teachers' access system have been established. School leader and head of the department lecture attendance rules have been stipulated (e.g., school leadership attend lecture above 10 times in a year). Teachers mutually attending lecture is the main way to know the effect of classroom teaching. Student representative writing class teaching log is a good way to help teacher manage the class teaching.

Studying and teaching situation analysis assessment meeting is scheduled at regular intervals, according to the lecture attending result and the class teaching log. Teaching effect and existing problems of class teaching management correction and supervision mechanism has been formed, taking student as the main body. Data analysis of evaluation system eliminates the distortion of malicious evaluation data respecting the autonomy of teachers in classroom management. Student assessment data is one of the grounds of teacher's annual economic distribution. It is also as a basis for teachers' psychological intervention(e.g., school leadership giving free talks to teachers with the poor teaching effect, setting up teachers quitting mechanism). Tracking and guidance mechanism to teachers with poor teaching effect has been established.

In order to consolidate the professional knowledge, a curriculum design quality process control mechanism has been built. The topic selection control highlights curriculum design focusing on the application and consolidation of professional knowledge, avoiding being conventional small graduation design. Project based learning emphasizes teaching content as the main body structure, designing synchronization with course teaching, topic selecting with engineering application background. The main knowledge points in the design demand to have direct calculations and hand-painted charts. Corresponding examination question bank has been set up, and student achievement assessment is completed by course design defense.

In order to improve students' ability of observation, experimental teaching quality control mechanisms have been constructed, reducing students' number of experimental group, putting the experimental teaching process and classroom teaching as the same standard, promoting experimental teachers and strengthening the experimental material, experimental instruments and equipment, laboratory experiment process management. Civil engineering fundamental experiments are opened to verifying knowledge, keeping pace with the courses teaching. The civil engineering comprehensive design experiments includes metal mechanics comprehensive performance(tension, pressure, bending, torsion), the comprehensive performance of concrete material, simply-supported reinforced concrete mechanics performance test and analysis(design, reinforcement, design of concrete, steel bar installation and concrete casting, the beam body and loading system test plan, test sensor installation), and the soil mechanics comprehensive performance test. Comprehensive experimental teaching system of cultivating the ability of students has been constructed at the same time. Students are encouraged to improving the ability of using knowledge innovation, comprehensive experiments (student design projects) by taking part in national and provincial college students' innovative entrepreneurial training program (SIT), schools, scientific research innovation (SRIP), and other innovative projects.

\section{Analysis of the result}

Project construction in our school of Talent Cultivation Mode Innovation Zone for Civil Engineering Specialty in Local Universities was from 2009 to 2014. Innovation of the research and practice has achieved remarkable results. By the innovation of the curriculum system, the practice and process control, students mastering many skills while specializing in all round multi-channel have been raised. students are encouraged to take part in all kinds of curriculum knowledge contest (e.g., measuring 
instrument operation competition, college students' mechanical competition), science and technology competition (e.g., structure modeling competition, college students challenge cup competition), college students' innovative projects (e.g., SIT, SRIP) or teachers' scientific research project. Students' ability to apply knowledge, innovation consciousness, and cooperation spirit have been trained and improved. During nearly six years, civil engineering students have completed 74 innovation projects supported by the national, provincial and other departments, won 49 national or provincial science and technology contest rewards, and more than 300 school-class rewards. Comprehensive practice for up to 15 weeks has effectively cultivated the students' knowledge application and innovation ability, interpersonal communication and coordination ability, social responsibility, consciousness of labor, and other comprehensive abilities. The effective mobilization, strict organization, entire journey instruction, process control, risk prevention, strict appraisal comprehensive practice for quality and safety monitoring mode has been established, which solved problem with student enrollment expansion, practice scheduling difficulties, poor practice quality, hidden danger in practice and effectively guaranteed the students' practice quality and personal safety. During comprehensive practice, students' knowledge, ability of solving practical problem increased significantly. While teachers contacting with students internship units and checking the internship process, link of the teachers and the enterprises has been effectively promoted, to further expand the scope of teacher technological services. The practice mode provides two-way choice platform for the students and employment units improving students' employment success rate. Nearly six years, civil engineering students in our school one-time employment rate has remained at more than 95\%, ranking top in our school. Class teaching level and teachers' recognition of the students have been improved; and annual check scores of more than 90\% teachers in civil engineering reach 95 points.

\section{Conclusion}

Talents cultivation mode effect evaluation need to be long-term tested and practiced. How to keep the era' characteristic and position civil engineering students of local universities main body status in social services to survive and develop in the fierce competition are the strong driving force of talents cultivation mode reformation. Exploring law of the Talents cultivation mode, carrying out teaching mode reformation and innovating Talents cultivation mode are the eternal missions of the institutions of higher education.

\section{Acknowledgment}

This paper is one of the staged achievements made by innovative experimental area project, Experimental Program of New Cultivation Mode for Civil Engineering High-quality Application-oriented Graduate in Local Colleges and Universities, from Department of Higher Education, Chinese Ministry of Education.

\section{References}

[1] Steering Committee for Civil Engineering Specialty in Institutions of Higher Learning, Undergraduate Teaching Objective, Program and Course Syllabus for Civil Engineering Specialty in Institutions of Higher Learning. China Architectural \& Building Press, 2002.

[2] Steering Committee for Civil Engineering Specialty in Institutions of Higher Learning, Undergraduate Guiding Specifications for Civil Engineering Specialty in Institutions of Higher Learning. China Architectural \& Building Press, 2011. 
[3] Lin Ling, "A review of the study on the talent cultivation mode of Institutions of higher learning," Journal of Sichuan Normal University (Social Sciences Edition), Vol. 35, July. 2008, pp.110-117.

[4] Zhu Gaofeng, "Chinese engineering education: present and future,” Tsinghua Journal of Education, Vol. 36, Jan. 2015, pp.47-50.

[5] Yang Guang, Zheng Xin, Liu Jinyun, and Guo Wei, "Construction method of curriculum systems for civil engineering specialty in local universities," Journal of Architectural Education in Institutions of Higher Learning, Vol. 36, Jan. 2015, pp.47-50.

[6] Li Yuke, Xu Jialin, and Wang Hui, "Mode and exploration of engineering innovation-oriented talent cultivation," Education Teaching Forum, Vol. 8, Feb. 2015, pp.65-66.

[7] Nie Yihua, Wang Qiren, Zhong Xingu, and Liu Lifang, "The practice study on cognition practice efficient model in civil engineering professional,” Teaching Seminars on Higher Education Science and Engineering Courses (HESEC2013), Dec. 2013, pp. 1065-1068.

[8] Nie Yihua, Zhong Xingu, Wang Qiren, and Liu Lifang, “The reformation on new practice model combining with civil engineering production practice and graduation practice," Journal of Educational Theories and Teaching and Research, Vol. 180, Nov. 2012, pp.14-15. 